\title{
Proteus empyema as a rare complication from an infected renal cyst, a case report
}

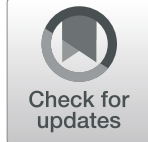

\author{
Kranthikiran Earasi ${ }^{{ }^{*}}$ (D), Caitlin Welch², Adam Zelickson ${ }^{3}$, Clinton Westover ${ }^{4}$, Chintan Ramani ${ }^{2}$, \\ Cameron Sumner ${ }^{5}$ and Eric M. Davis ${ }^{2}$
}

\begin{abstract}
Background: The most commonly isolated organisms in a parapneumonic effusion include S. pneumoniae, $H$. influenzae, and S. aureus. If unusual organisms are isolated from the pleural space, further investigation is warranted to locate the primary source. We present a patient with an infected chronic renal cyst found to have an empyema secondary to Proteus mirabilis to highlight the importance of further diagnostic workup when encountering unusual organisms in the pleural space.
\end{abstract}

Case presentation: A 40-year-old African-American female, with a past medical history of asthma and sickle cell trait, presented with 5 weeks of upper respiratory tract symptoms and chest pain. A computed tomography angiogram (CTA) of the chest was negative for a pulmonary embolism but revealed a loculated left sided pleural effusion with associated left-lower lobe consolidation. She was started on empiric antibiotics, and a chest tube was inserted with drainage of frank pus. Fluid gram stain was positive for gram negative rods.

Intrapleural fibrinolytics were administered for $72 \mathrm{~h}$ given the presence of loculations. With no improvement following fibrinolytics, she was taken to the operating room for large bore chest tube placement and left visceral pleura decortication. Pleural fluid cultures speciated to Proteus mirabilis, so further cross-sectional imaging of her abdomen/pelvis was pursued to evaluate for a primary source. A complex cystic lesion in the upper pole of the left kidney that communicated with the ipsilateral diaphragm was identified. Subsequent drainage and culture of the renal cyst was positive for Proteus mirabilis. Given clinical improvement following these interventions she was discharged with an extended course of antibiotics with plans for repeat imaging following completion of treatment.

Conclusions: While cases of Proteus mirabilis empyema have previously been reported as a consequence of conditions such as pyelonephritis, we present, to our knowledge, the first case of a Proteus mirabilis empyema as a consequence of an infected renal cyst communicating with the pleural space. This study highlights that further evaluation with cross-sectional imaging is warranted when unusual organisms are found in the pleural space. Anatomic abnormalities that become apparent on imaging may help elucidate the source of infection.

Keywords: Empyema, Proteus, Renal cyst, Case report, Computed tomography

\footnotetext{
* Correspondence: Ke3uh@hscmail.mcc.virginia.edu

Notation of prior abstract publication/presentation: Abstract published in

American Journal of Respiratory and Critical Care Medicine in 2020 with

ePoster presentation in August of 2020

'Department of Medicine, University of Virginia, 1714 Calvary Circle, Apt. 302,

Charlottesville, VA 22911, USA

Full list of author information is available at the end of the article
}

(c) The Author(s). 2020 Open Access This article is licensed under a Creative Commons Attribution 4.0 International License, which permits use, sharing, adaptation, distribution and reproduction in any medium or format, as long as you give appropriate credit to the original author(s) and the source, provide a link to the Creative Commons licence, and indicate if changes were made. The images or other third party material in this article are included in the article's Creative Commons licence, unless indicated otherwise in a credit line to the material. If material is not included in the article's Creative Commons licence and your intended use is not permitted by statutory regulation or exceeds the permitted use, you will need to obtain permission directly from the copyright holder. To view a copy of this licence, visit http://creativecommons.org/licenses/by/4.0/ The Creative Commons Public Domain Dedication waiver (http://creativecommons.org/publicdomain/zero/1.0/) applies to the data made available in this article, unless otherwise stated in a credit line to the data. 


\section{Background}

The most commonly isolated organisms in a parapneumonic effusion include S. pneumoniae, $H$. influenzae, and $S$. aureus [1]. If unusual organisms are isolated from the pleural space, further investigation is warranted to locate the primary source. While Enterobacteria, Pseudomonas spp., and M. tuberculosis may comprise some of these unusual organisms, some of which are more commonly found in nosocomial infections, the gram negative bacteria Proteus mirabilis may also be isolated [2-4]. Known as one of the leading causes of pyelonephritis and urolithiasis, few case studies exist reporting its presence in the pleural space, and those present only describe the presence of this bacteria in the pleural space in the setting of an underlying pyonephrosis/pyelonephritis [5-7]. To our knowledge, there has been no association between Proteus related pleural disease and chronic renal disease. We present a patient with an infected chronic renal cyst found to have an empyema secondary to Proteus mirabilis to highlight the importance of further diagnostic workup when encountering unusual organisms in the pleural space.

\section{Case presentation}

A 40-year-old African American female presented to our institution with 5 weeks of upper respiratory tract symptoms and chest pain. Her past medical history was significant for asthma, type 2 diabetes, hypertension, and sickle cell trait. Prior to admission, she was seen at urgent care centers and her symptoms were attributed to a viral illness and supportive care was recommended. Given worsening dyspnea on exertion, she presented to the emergency room for further evaluation. Initial vital signs were notable for a temperature of $100.5^{\circ}$ Fahrenheit, heart rate of 107, respiratory rate of 30 breaths per minute, blood pressure of $126 / 75$, and an oxygen saturation of $95 \%$ on 21 per minute of supplemental oxygen. Physical examination on arrival was notable for diaphoresis, tachypnea, diminished breath sounds in the left lung base as well as dullness to percussion over the left lower lung field, and tenderness to palpation in the left upper quadrant of the abdomen. Workup with a computed tomography angiogram (CTA) of the chest did not show evidence of a pulmonary embolism but was notable for a loculated left sided pleural effusion with associated left lower lobe consolidation. She was started on ceftriaxone and azithromycin empirically, and a chest tube was inserted which resulted in drainage of frank pus. Fluid analysis showed a WBC of 210,200 cells/uL, LDH of 12,915 units/L, and a pleural fluid $\mathrm{pH}$ of 6.2. A gram stain was positive for gram negative rods.

Intrapleural fibrinolytics with tissue plasminogen activator (tPA) and deoxyribonuclease (DNAse) were administered for $72 \mathrm{~h}$ given the presence of loculations. With no significant improvement following fibrinolytics, she was taken to the operating room for large bore chest tube placement and video-assisted thoracoscopic surgery (VATS) decortication of the left visceral pleura. Pleural fluid cultures speciated to Proteus mirabilis (Fig. 1), so she underwent further imaging to evaluate for a primary source. Computed tomography $(\mathrm{CT})$ abdomen/pelvis revealed a complex cystic lesion in the upper pole of the left kidney that communicated with the ipsilateral diaphragm (Figs. 2 and 3). Urinalysis on presentation was unremarkable. A drainage catheter was placed within this abscess, and culture of the cyst fluid was also positive for Proteus mirabilis.

The patient clinically improved following these interventions and was transitioned to intravenous ceftriaxone and metronidazole following culture

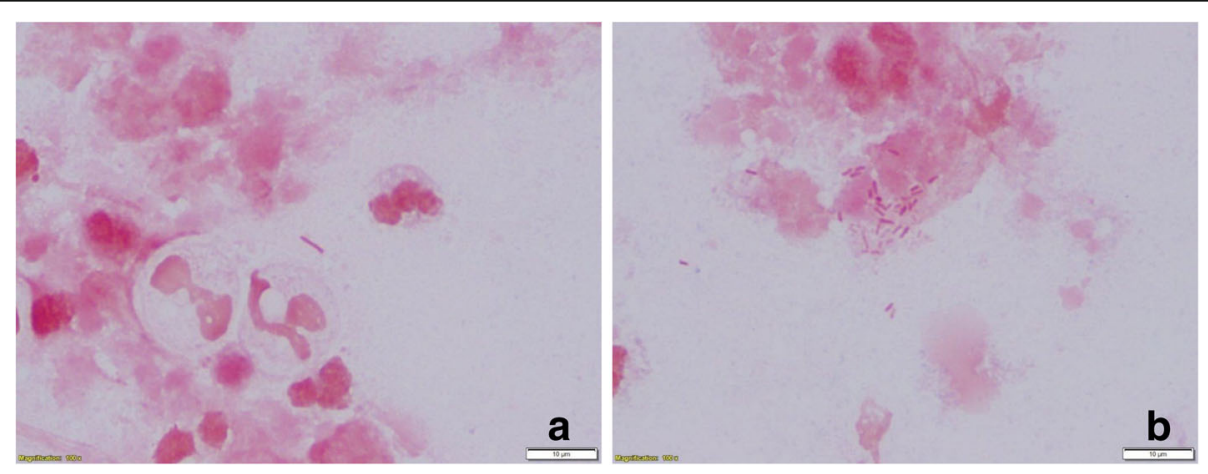

Fig. 1 Microscopic view of Proteus mirablils in the patient's pleural fluid with the black arrows indicating Proteus species. (a and b) 


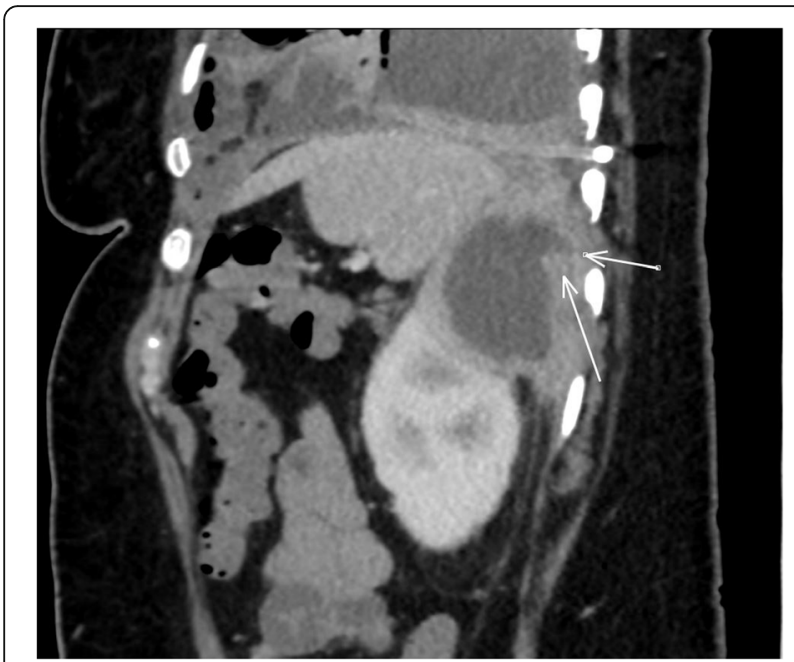

Fig. 2 Computed Tomography results showing a sagittal cross section of the patient's abdomen with the white arrows indicating the renal cyst and tract extending posteriorly to the diaphragm speciation. At the completion of a 12 day hospitalization, she was discharged to home on an extended course of oral amoxicillin-clavulanate. Repeat CT chest and CT abdomen/pelvis 18 days post discharge, following the completion of the antibiotic course, showed interval resolution of the renal cyst and left sided empyema.

\section{Discussion and conclusions}

While cases of Proteus mirabilis empyema have previously been reported as a consequence of conditions such as pyelonephritis, we present, to our knowledge, the first case of a Proteus mirabilis empyema as a consequence of an infected renal cyst communicating with the pleural space. A prior case series identified Proteus mirabilis in the pleural fluid of three separate patients who had effusions secondary to either metastatic malignancy or heart failure. Despite the different etiologies, all three effusions were alkalotic with an average $\mathrm{pH}$ of 7.77 [8]. The alkalinity of the fluid was hypothesized to be the result of the urease producing ability of Proteus. The measurement of pleural fluid $\mathrm{pH}$ along with pleural ammonia levels were thought to be of diagnostic utility when considering Proteus as a causative organism [8]. Though our patient's pleural fluid $\mathrm{pH}$ was 6.2 , the use of procedural lidocaine may explain this discrepancy from the findings of the aforementioned study [9].

Our case presented an otherwise healthy female with few comorbidities who was found to have an empyema secondary to Proteus. Despite the infected chronic renal cyst, her lack of urinary symptoms or abnormal urinalysis is consistent with prior cases of Proteus-related lung infections, demonstrating the importance of considering an intra-abdominal source of infection in these cases [10].

This study highlights that further evaluation with cross-sectional imaging should be considered when

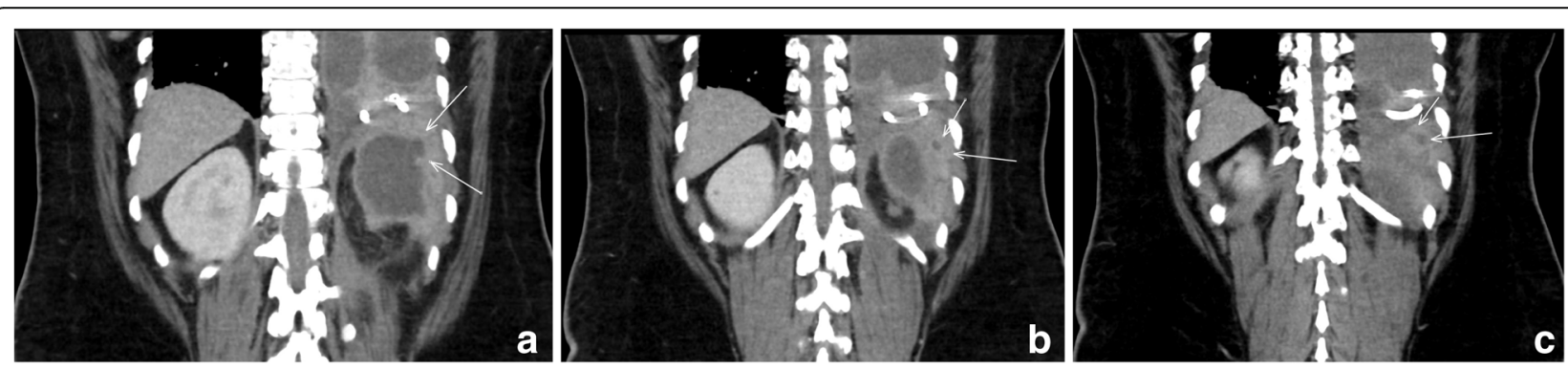

Fig. 3 Computed Tomography results showing sequential coronal cross sections of the patient's abdomen extending posteriorly with the white arrows indicating the posteriorly and superiorly extending tract from the renal cyst to the diaphragm. (Anterior to Posterior (Left to Right): $\mathbf{a}$, $\mathbf{b}$, and c) 
unusual organisms are found in the pleural space. Anatomic abnormalities that become apparent on imaging may help elucidate the source of infection. In combination with laboratory markers, radiologic findings can prove to be of equal importance in guiding treatment.

\section{Abbreviations}

CTA: Computed tomography angiogram; CT: Computed tomography; DNAse: Deoxyribonuclease; LDH: Lactate Dehydrogenase; tPA: Tissue plasminogen activator; VATS: Video-assisted thoracoscopic surgery; WBC: White Blood Cell

\section{Acknowledgments}

None.

\section{Authors' contributions}

KE primarily drafted the manuscript and arranged the Figs. CW was a major contributor in writing and reviewing the manuscript. AZ performed the interpretation of the radiology films that assisted with diagnosis of the patient. CW performed the histological examination of the pleural fluid which identified the presence of Proteus mirabilis. CR was a major contributor in writing and reviewing the manuscript. CS was a major contributor in writing and reviewing the manuscript. ED served as the primary investigator and was a major contributor in writing and reviewing the manuscript. All authors read and approved the final manuscript.

\section{Authors' information}

Not applicable.

\section{Funding}

Not applicable.

\section{Availability of data and materials}

No raw data was utilized in the production of this manuscript. Only information pertaining to this patient's hospital course as documented in our institution's electronic medical record was utilized in the creation of this work.

\section{Ethics approval and consent to participate}

Not applicable.

\section{Consent for publication}

Consent was obtained from the patient for publication of this manuscript in the form of a verbal consent as well as a written consent in the form of an email. Verbal consent was also obtained given the patient's remote living situation with respect to our institution and infrequent need for follow up. No identifying features (both in the text and images) were included in the manuscript.

\section{Competing interests}

The authors declare that they have no competing interests.

\section{Author details}

${ }^{1}$ Department of Medicine, University of Virginia, 1714 Calvary Circle, Apt. 302, Charlottesville, VA 22911, USA. ${ }^{2}$ Division of Pulmonary and Critical Care Medicine, Department of Medicine, University of Virginia, Charlottesville, VA, USA. ${ }^{3}$ Department of Radiology, University of Virginia, Charlottesville, VA, USA. ${ }^{4}$ Department of Pathology, University of Virginia, Charlottesville, VA, USA. ${ }^{5}$ Department of Anesthesiology, University of Virginia, Charlottesville, VA, USA

Received: 1 April 2020 Accepted: 12 November 2020

Published online: 27 November 2020

\section{References}

1. McCauley L, Dean N. Pneumonia and empyema: causal, casual or unknown. J Thorac Dis. 2015;7(6):992-8.

2. Chapman S, Robert J. The management of pleural space infections. Respirology. 2004;9(1):4-11.
3. Rosenstengel A. Pleural infection-current diagnosis and management. J Thorac Dis. 2012;4(2):186

4. Patel S, Holland S, Fullerton D. P. mirabilis Pleural Empyema Secondary to a Staghorn Calculus in the Left Kidney. Am Thorac Soc. 2018:A3597.

5. O'Hara C, Brenner F, Miller J. Classification, identification, and clinical significance of Proteus, Providencia, and Morganella. Clin Microbiol Rev. 2000;13(4):534-46.

6. Hernández $P$, Suárez R, Gilart F. Pleural empyema secondary to pyonephrosis. Arch Bronconeumol. 2008;44(5):285.

7. Lacort F, Gutierrez F, Gonzalez R, Antuna B, Herrero F, Espina A. Massive pleural empyema caused by pyonephrosis. An Med Interna. 2001;18(3):1478.

8. Pine J, Hollman J. Elevated pleural fluid $\mathrm{pH}$ in Proteus mirabilis empyema. Chest. 1983;84(1):109-11.

9. Rahman N, Mishra E, Davies H, Davies R, Lee Y. Clinically important factors influencing the diagnostic measurement of pleural fluid $\mathrm{pH}$ and glucose. Am J Respir Crit Care Med. 2008;178(5):483-90.

10. Tillotson J, Lerner A. Characteristics of pneumonias caused by Bacillus proteus. Ann Intern Med. 1968;68(2):287-94

\section{Publisher's Note}

Springer Nature remains neutral with regard to jurisdictional claims in published maps and institutional affiliations.

\section{Ready to submit your research? Choose BMC and benefit from:}

- fast, convenient online submission

- thorough peer review by experienced researchers in your field

- rapid publication on acceptance

- support for research data, including large and complex data types

- gold Open Access which fosters wider collaboration and increased citations

- maximum visibility for your research: over $100 \mathrm{M}$ website views per year

At $\mathrm{BMC}$, research is always in progress.

Learn more biomedcentral.com/submissions 